\title{
Infection Status of Gnathostoma spinigerum Larvae in Asian Swamp Eels, Monopterus albus, Purchased from Local Markets in Cambodia
}

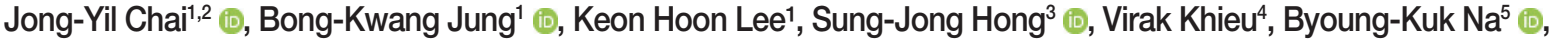 \\ Woon-Mok Sohn ${ }^{5, *}$ (i)
}

\begin{abstract}
1'Institute of Parasitic Diseases, Korea Association of Health Promotion, Seoul 07649, Korea; '2Department of Tropical Medicine and Parasitology, Seoul National University College of Medicine, Seoul 03080, Korea; ${ }^{2}$ Department of Environmental Medical Biology, Chung-Ang University College of Medicine, Seoul 06974, Korea; ${ }^{4}$ National Center for Parasitology, Entomology and Malaria Control, Ministry of Health, Phnom Penh, Cambodia; ${ }^{5}$ Department of Parasitology and Tropical Medicine, and Institute of Health Sciences, Gyeongsang National University College of Medicine,
\end{abstract} Jinju 52727, Korea

\begin{abstract}
Present study was performed to know the infection status of Gnathostoma sp. larvae in swamp eels from Cambodia. We purchased total 30 Asian swamp eels, Monopterus albus, from local markets in Pursat and Takeo Provinces and Phnom Penh on May and November 2017 and May 2018. All collected eels were transferred to our laboratory with ice and each of them was examined by artificial digestion method. A total of 15 larval gnathostomes (1-5 larvae) were detected from 55.6\% (5/9) swamp eels in Pursat Province. No larval gnathostomes were found in 21 swamp eels in Takeo Province and Phnom Penh. The advanced third-stage larvae $\left(\mathrm{AdL}_{3}\right)$ detected were 2.575-3.825 (3.250) $\mathrm{mm}$ in length and $0.375-0.425(0.386) \mathrm{mm}$ in width. They had the characteristic head bulb (av. $0.104 \times 0.218 \mathrm{~mm}$ ) with 4 rows of hooklets, long muscular esophagus $(1.048 \mathrm{~mm})$, and 2 pairs of cervical sacs $(0.615 \mathrm{~mm})$. The number of hooklets in 4 rows on the head bulb was 41, 44, 47, and 50. In scanning electron microscopy, characteristic features were 4 rows of hooklets on the head bulb, cervical papillae, tegumental spines regularly arranged in transverse striations, and anus. The larval gnathostomes were identified as $\mathrm{AdL}_{3}$ of Gnathostoma spinigerum based on the morphological characters. By the present study, it has been confirmed that G. spinigerum larvae are infected in Asian swamp eels, M. albus, in Pursat Province, Cambodia.
\end{abstract}

Key words: Gnathostoma spinigerum, Monopterus albus, advanced 3rd-stage larva, Asian swamp eel, Pursat Province, Cambodia

Nematode parasites of the genus Gnathostoma are clinically important as etiologic agents of foodborne zoonoses in humans. Among 13 valid species, only 6, i.e., G. binucleatum, G. doloresi, G. hispidum, G. malaysiae, G. nipponicum, and G. spinigerum, are known to be pathogens in humans. Infection with larval gnathostomes, gnathostomiasis, is clinically characterized by creeping eruption in subcutaneous and intermuscular tissues due to migrating larvae. The larvae occasionally invade the visceral organs, including the liver, lungs, eyes, and even the brain $[1,2]$.

In Cambodia, gnathostomiasis is very rare whereas it is relatively prevalent in neighboring countries, i.e., Thailand, Lao

\footnotetext{
- Received 1 November 2020, revised 2 December 2020, accepted 3 December 2020. *Corresponding author (wmsohn@gnu.ac.kr) (c) 2020, Korean Society for Parasitology and Tropical Medicine This is an Open Access article distributed under the terms of the Creative Commons Attribution Non-Commercial License (https://creativecommons.org/licenses/by-nc/4.0) which permits unrestricted non-commercial use, distribution, and reproduction in any medium, provided the original work is properly cited.
}

PDR, and Myanmar [3-10]. Only 1 case of ocular gnathostomiasis was recently reported in Cambodia [11]. Larval gnathostomes recovered from Asian swamp eels, Monopterus albus, were molecularly identified as G. spinigerum in Cambodia [12]. There are no other available studies to refer in Cambodia. Thus, we carried out a survey to know the infection status of Gnathostoma larvae in Asian swamp eels, which have been known as the most susceptible fish host for G. spinigerum, purchased in local markets in Pursat and Takeo Provinces, and Phnom Penh, Cambodia. Additionally, we observed the morphological characteristics of larval gnathostomes detected in Cambodia with a light microscope and a scanning electron microscope (SEM).

A total of 30 Asian swamp eels (Fig. 1A) were purchased in local markets in Pursat ( $\mathrm{n}=9$; 41-67 cm in length, 61-453 g in weight, and examined on May 2017), Takeo ( $\mathrm{n}=11 ; 47-65 \mathrm{~cm}$ in length, 120-292 g in weight, and on November 2017) Provinces and Phnom Penh ( $\mathrm{n}=10 ; 53-61 \mathrm{~cm}$ in length, 143-237 g 
in weight, and on May 2018), Cambodia. All collected eels were transferred with ice to the laboratory in the Department of Parasitology and Tropical Medicine, Gyeongsang National University College of the Medicine and measured the length and weight of the fish (Table 1). Individual fish was finely ground in a mortar with pestle, the ground meat was mixed well with artificial gastric juice, and the mixture was incubated at $36^{\circ} \mathrm{C}$ for about $2 \mathrm{hr}$. The digested material was filtered with a sieve $\left(5 \times 5 \mathrm{~mm}^{2}\right.$ of mesh), and washed with $0.85 \%$ saline until the supernatant became clear. The sediment was carefully examined under a stereomicroscope and then larvae were separately collected based on the general features [13]. Some de-
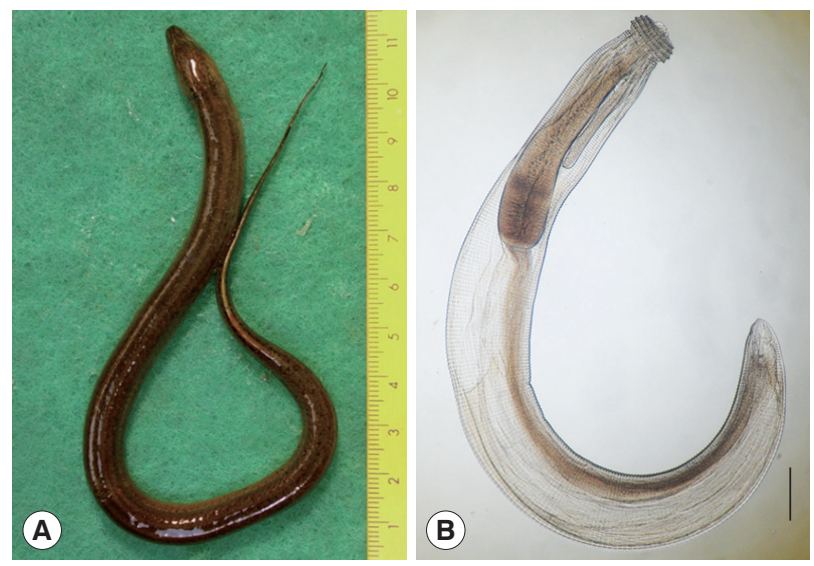

Fig. 1. (A) An Asian swamp eel, Monopterus albus, from a local market in Pursat province, Cambodia. (B) An advanced 3rd stage larva of $\mathrm{G}$. spinigerum collected in an Asian swamp eel from a local market in Pursat province, Cambodia. It has a characteristic head bulb with characteristic 4 rows of hooklets, muscular esophagus and intestine, and 4 cervical sacs. Scale bar $=0.25$ $\mathrm{mm}$. tected larvae were fixed with $10 \%$ hot formalin and mounted with glycerine-jelly after clearing in alcohol-glycerine solution to observe the morphological characteristics. To observe the surface ultrastructure, some larval gnathostomes were washed several times in $0.2 \mathrm{M}$ cacodylate buffer (pH 7.2) and fixed in $2.5 \%$ glutaraldehyde at $4^{\circ} \mathrm{C}$. After washing 3 times with the same buffer, they were dehydrated through a graded alcohol series $(50 \%, 70 \%, 80 \%, 90 \%, 95 \%$, and absolute alcohol), dried in a desiccator with silicagels after treatment with hexamethyldisilazane, coated with gold in the JFC-1100E ion sputtering device (JEOL, Tokyo, Japan), and observed using a scanning electron microscope (Jeol JSM-7610F, Tokyo, Japan) at an accelerating voltage of $5.0 \mathrm{kV}$.

Total 15 larval gnathostomes (1-5 larvae) were detected in 5 (55.6\%) out of 9 swamp eels from Pursat Province. No larval gnathostomes were found in 21 swamp eels from Takeo Province and Phnom Penh.

The detected gnathostome larvae (advanced 3rd-stage; $\mathrm{AdL}_{3}$ ) were 2.575-3.825 (av. 3.250) $\mathrm{mm}$ in length and 0.375-0.425 (0.386) $\mathrm{mm}$ in width (Fig. 1B). They had the characteristic head bulb (av. $0.104 \times 0.218 \mathrm{~mm}$ ) with 4 rows of hooklets, long muscular esophagus (av. $1.048 \mathrm{~mm}$ ), and 2 pairs of cervical sacs (av. $0.615 \mathrm{~mm}$ ). The number of hooklets in the 1st, 2nd, 3rd, and 4th row was 41, 44, 47, and 50 in average, respectively. Most of these morphological findings were similar with those of our previous study, Chai et al. [13] (Table 1).

In SEM observations, whole worms of $\mathrm{AdL}_{3}$ obviously possessed a head bulb with 4 transverse rows of hooklets and cuticular spines on the transverse striations of body surface (Fig.

Table 1. Comparison of measurements ${ }^{\mathrm{a}}$ of the advanced third-stage larvae of Gnathostoma spinigerum detected from Asian swamp eels, Monopterus albus, with those of a previous study

\begin{tabular}{lcc}
\hline Organs measured & Present study (2020) & Chai et al. [13] (2015) $^{\mathrm{b}}$ \\
\hline Body, length & $2.575-3.825(3.250)$ & $2.300-4.400(3.347)$ \\
$\quad$ width & $0.375-0.425(0.386)$ & $0.250-0.425(0.366)$ \\
Head bulb, length & $0.095-0.115(0.104)$ & $0.075-0.115(0.093)$ \\
$\quad$ width & $0.175-0.235(0.218)$ & $0.165-0.250(0.221)$ \\
Esophagus, length & $0.950-1.150(1.048)$ & $0.630-1.220(1.025)$ \\
Cervical sac, length & $0.510-0.720(0.615)$ & $0.330-0.750(0.574)$ \\
Tail, length & $0.030-0.060(0.044)$ & $0.040-0.110(0.071)$ \\
No. of hooklets on the head bulb & & $38-44(41)$ \\
1st row & $39-42(41.0)$ & $42-50(45)$ \\
2nd row & $42-45(43.7)$ & $44-52(48)$ \\
3rd row & $45-49(46.5)$ & $48-54(51)$ \\
4th row & $49-52(50.3)$ & \\
\hline
\end{tabular}

aUnit is $\mathrm{mm}$ (average).

Each of $6^{b}$ and $29^{c} A d L_{2}$ (from Myanmar swamp eels) were measured. 

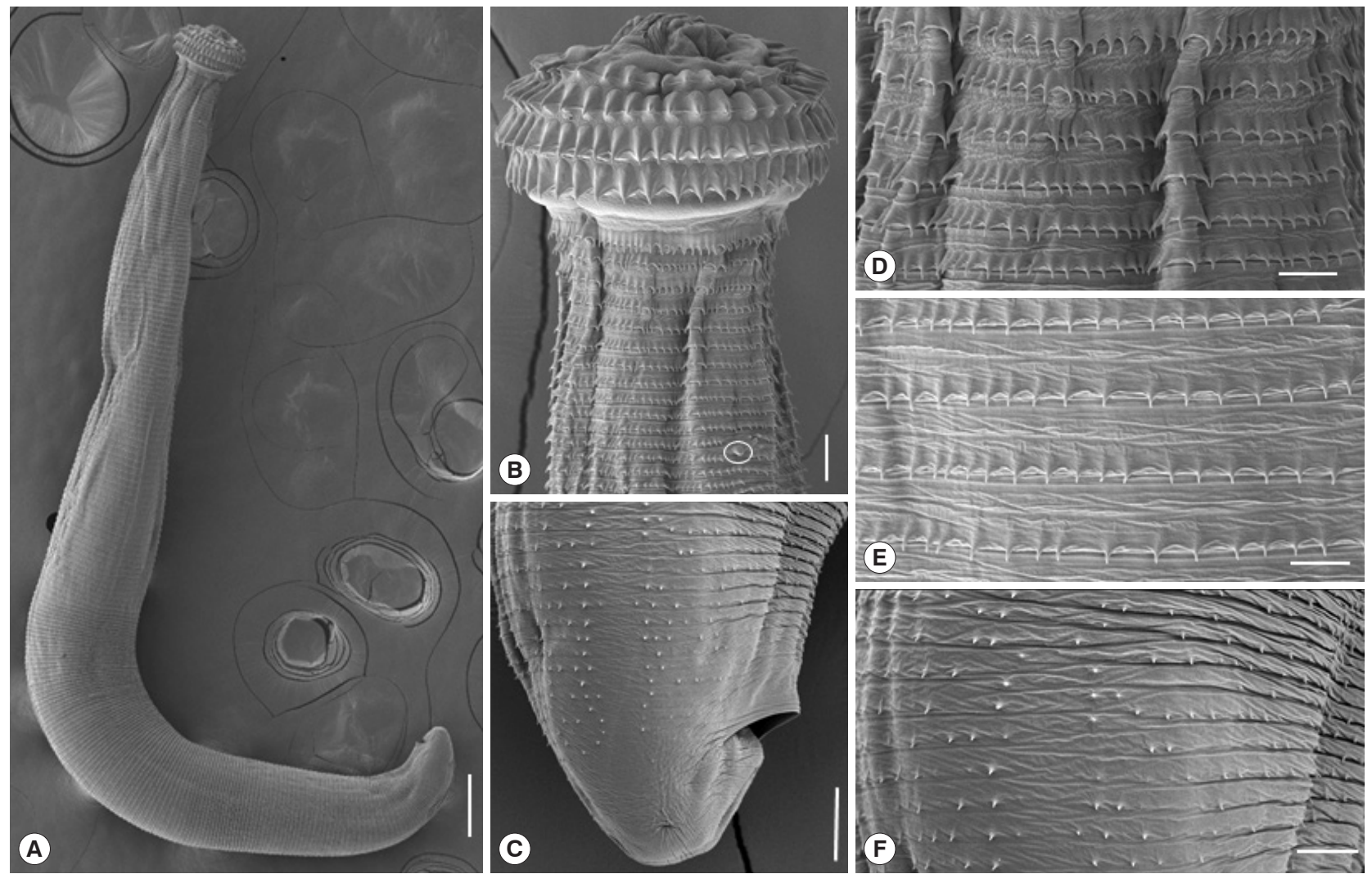

Fig. 2. Scanning electron micrographs of the $A_{d L}$ of $G$. spinigerum from Asian swamp eels in Pursat Province, Cambodia. (A) Whole body showing a head bulb, numerous transverse striations with cuticular spines, and an anus. Scale bar $=200 \mu \mathrm{m}$. (B) The head bulb bearing 4 transverse rows of hooklets and a cervical papilla located between the 12th and 13th transverse striations (encircled). Scale bar $=20 \mu \mathrm{m}$. (C) Posterior end of a larva having smaller cuticular spines on the transverse striations and an anus. Scale bar $=20 \mu \mathrm{m}$. (D) Tegumental surface in anterior portion having transverse striations with numerous cuticular spines. Scale bar $=10 \mu \mathrm{m}$. (E) Tegumental surface in middle portion having transverse striations with cuticular spines more or less sparsely distributed than in the anterior portion. Scale bar $=10 \mu \mathrm{m}$. (F) Tegumental surface in posterior portion having smaller cuticular spines sparsely distributed on the transverse striations. Scale bar $=10 \mu \mathrm{m}$.

2A). A pair of lips were located at the anterior end of the body. The hooklets on the head bulb were somewhat curved posteriorly and had a sharp-pointed end. A cervical papilla was located between the 12th and 13th transverse striations (Fig. 2B). An anus was backwardly opened near the posterior end (Fig. 2C). Cuticular spines with a sharp-point were regularly arranged on the transverse striations of the tegument, and they were densely distributed on the tegumental surface of the anterior part and gradually decreased in size and number posteriorly (Fig. 2D, E). On the tegument near the posterior end, smaller cuticular spines were more sparsely distributed (Fig. 2F).

The Asian swamp eel, M. albus, has been frequently investigated to know the infection status of gnathostome larvae in Southeast Asian countries, such as Myanmar, Vietnam, and Thailand [13-19]. Chai et al. [13] examined 37 swamp eels collected in a local market of Yangon, Myanmar. Sieu et al. [14] surveyed the infection status of G. spinigerum $\mathrm{AdL}_{3}$ in wild swamp eels collected from 2 localities, i.e., Long An Province and Hoc Mon district of Ho Chi Minh City, in southern Vietnam. Le and Rojekittikhun [15] examined the infections of Gnathostoma spp. larvae in 1,081 swamp eels purchased from a local market in Ho Chi Minh City, Vietnam. Saksirisampant and Thanomsub [16] surveyed total 1,420 livers of swamp eels from a farm (1,037 eels) in Aranyaprathet district, Sa Kaeo Province and those from 383 wild-caught eels of Min Buri district, Bangkok, Thailand. Rojekittikhun et al. [17] examined 1,844 swamp eels purchased from several local markets in Nakhon Nayok Province, Thailand. Sugaroon and Wiwanitkit [18] and Saksirisampant et al. [19] surveyed the infection sta-

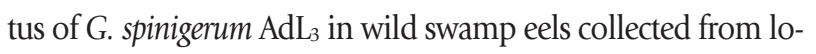


cal markets in Bangkok, Thailand. Even in USA, Cole et al. [20] examined 47 imported swamp eels purchased in fish markets and 67 wild-caught specimens. In Cambodia, there has been no study on the infection status with larval gnathostomes in swamp eels although a molecular study was performed on larval gnathostomes recovered in the livers of swamp eels from Siem Reap Province [12]. On the other hand, Asian swamp eels are relatively expensive and favored food-material in Southeast Asian countries. However, like freshwater eels, Anguilla japonica, in Korea, the swamp eels are not consumed raw in these countries. Their muscles are very hard to eat raw. Thus, the survey on the infection status with larval gnathostomes in swamp eels is to obtain the reference data in the aspect of gnathostomiasis epidemiology in endemic areas. As Asian swamp eel is a kind of susceptible fish host, it is used as the index fish species in the survey of larval gnathostome infections.

We examined only 30 Asian swamp eels purchased in local markets in 3 localities, Phnom Penh, Pursat and Takeo Provinces, Cambodia through 3 times on May and November 2017 and May 2018. Due to the transportation difficulty of fish specimens with ice from Cambodia to Korea, we could not investigate an enough number of fish samples, and then we could not know the infection trend with larval gnathostomes in Asian swamp eels by seasons and localities in Cambodia. Both the prevalence and infection intensity were higher during August-October in Vietnam [14], and were highest in rainy seasons (June-July) in Thailand [16-19]. However, in Myanmar, the prevalence was higher in December, and the infection intensity was higher in June [13]. Discrepancy between the prevalence and infection intensity may have been caused by the small number of fish examined in Myanmar. On the other hand, the species identification of larval Gnathostoma $\left(\mathrm{AdL}_{3}\right)$ is mainly done by the number and distribution of hooklets on the head bulb. In case of G. spinigerum, the number of hooklets is more than 40 in each row and reveals an increasing tendency posteriorly [1]. In the present study, the larval gnathostomes were identified as $\mathrm{AdL}_{3}$ of $G$. spinigerum because of the hooklet numbers on each row of the head bulb was 41,44 , 47 , and 50 in average.

In the present study, a total of 15 (3.0 per fish infected) larval gnathostomes were detected from 5 (16.7\%) out of 30 swamp eels examined. Moreover, the larvae were found only in swamp eels from Pursat Province and were not detected in swamp eels from other 2 localities, Phnom Penh and Takeo Province. Chai et al. [13] detected total 401 (12.2 per fish in- fected) larval gnathostomes in 33 (89.2\%) out of 37 swamp eels from Yangon, Myanmar. Sieu et al. [14] found total 1,008 (8.1 per fish infected) larvae in 125 (4.4\%) out of 2,830 wild swamp eels collected in Long An Province and Hoc Mon district of Ho Chi Minh City, Vietnam. Saksirisampant and Thanomsub [16] collected total 674 (3.7 per fish infected) larvae in $184(13.0 \%)$ out of 1,420 livers of swamp eels from Bangkok, Thailand. Rojekittikhun et al. [17] reported 30.1\% prevalence and 10.0 larvae per fish infected (mean intensity of infection) in 1,844 swamp eels from several local markets in Nakhon Nayok Province, Thailand. Sugaroon and Wiwanitkit [18] detected the third stage larvae of G. spinigerum from 466 (26.1\%) out of 1,788 livers of swamp eels collected at a metropolitan market in Bangkok, Thailand. Saksirisampant et al. [19] found Gnathostoma spp. $\mathrm{AdL}_{3}$ (4.0 per fish liver infected) in $524(19.1 \%)$ out of 2,738 livers of swamp eels from Klong Toey market in Bangkok, Thailand. Cole et al. [20] found total $36 \mathrm{AdL}_{3}$ of G. spinigerum (2.8 per fish infected) in 13 (27.7\%) out of 47 swamp eels, which were imported to USA. By the present study, it has been confirmed that the prevalence and infection intensity of larval gnathostomes are much lower in swamp eels from Cambodia than in those from Myanmar, Vietnam, and Thailand, and even in imported ones to USA.

\section{ACKNOWLEDGMENTS}

We thank Jung-A Kim and Hee-Joo Kim (Department of Parasitology and Tropical Medicine, Gyeongsang National University College of Medicine, Jinju, Korea), for their help in the examination of fish. We also thank all members of KAHP (Korea Association of Health Promotion) who participated in the survey for intermediate hosts of Echinostoma spp. (May 2017), the investigation of the infection status of intestinal parasites in Cambodia (November 2017), and the investigation of intestinal trematode infections for schoolchildren and residents in Cambodia (May 2018).

\section{CONFLICT OF INTEREST}

The authors have no conflicts of interest concerning the work reported in this paper.

\section{REFERENCES}

1. Miyazaki I. Section III. Nematode Zoonoses. 33. Gnathostomia- 
sis. An Illustrated Book of Helminthic Zoonoses. Tokyo, Japan. International Medical Foundation of Japan. 1991, pp 368-409.

2. Herman JS, Chiodini PL. Gnathostomiasis, another emerging imported disease. Clin Microbiol Rev 2009; 22: 484-492. https:// doi.org/10.1128/CMR.00003-09

3. Bussaratid V, Dekumyoy P, Desakorn V, Jaroensuk N, Liebtawee B, Pakdee W, Wattanagoon Y. Predictive factors for Gnathostoma seropositivity in patients visiting the gnathostomiasis clinic at the hospital for tropical diseases, Thailand during 2000-2005. Southeast Asian J Trop Med Public Health 2010; 41: 1316-1321.

4. Jongthawin J, Intapan PM, Sanpool O, Sadaow L, Janwan P, Thanchomnang T, Sangchan A, Visaetsilpanonta S, Keawkong W, Maleewong W. Three human gnathostomiasis cases in Thailand with molecular identification of causative parasite species. Am J Trop Med Hyg 2015; 93: 615-618. https://doi.org/10.4269/ajtmh. 15-0284

5. Hennies F, Jappe U, Kapaun A, Enk A. Gnathostomiasis: import from Laos. J Dtsch Dermatol Ges 2006; 4: 414-416. https://doi. org/10.1111/j.1610-0387.2006.05942.x

6. Vonghachack Y, Dekumyoy P, Yoonuan T, Sa-nguankiat S, Nuamtanong S, Thaenkham U, Phommasack B, Kobayashi J, Waikagul J. Sero-epidemiological survey of gnathostomiasis in Lao PDR. Parasitol Int 2010; 59: 599-605. https://doi.org/10.1016/j.parint. 2010.08.007

7. Nomura Y, Nagakura K, Kagei N, Tsutsumi Y, Araki K, Sugawara M. Gnathostomiasis possibly caused by Gnathostoma malaysiae. Tokai J Exp Clin Med 2000; 25: 1-6.

8. Chai JY, Han ET, Shin EH, Park JH, Chu JP, Hirota M, Nakamura-Uchiyama F, Nawa Y. An outbreak of gnathostomiasis among Korean emigrants in Myanmar. Am J Trop Med Hyg 2003; 69: 67-73.

9. Develoux M, Dekumyoy P, Baygon E, Aractingi S. Imported gnathostomiasis acquired in Myanmar. Med Mal Infect 2006; 36: 340342 (in French). https://doi.org/10.1016/j.medmal.2006.01.011

10. Wai AP, Maw WW, Moe AC, Boonmars T, Nawa Y. Human gnathostomiasis in Myanmar: a review of local literature. Southeast Asian J Trop Med Public Health 2018; 49: 543-548.

11. Hem S, Tarantola A, Chheang R, Nop P, Kerléguer A. First reported case of intraocular Gnathostoma spinigerum in Cambodia. Bull Soc Pathol Exot 2015; 108: 312-315. https://doi.org/10.1007/s13149-
015-0453-2

12. Boonroumkaew P, Sanpool O, Rodpai R, Sadaow L, Somboonpatarakun C, Laymanivong S, Aung WPP, Un M, Laummaunwai P, Intapan PM, Maleewong W. Molecular identification and genetic diversity of Gnathostoma spinigerum larvae in freshwater fishes in southern Lao PDR, Cambodia, and Myanmar. Parasitol Res 2019; 118: 1465-1472. https://doi.org/10.1007/s00436-01906292-Z

13. Chai JY, Sohn WM, Na BK, Park JB, Jeoung HG, Hoang EH, Htoon TT, Tin HH. Larval Gnathostoma spinigerum detected in Asian swamp eels, Monopterus albus, purchased from a local market in Yangon, Myanmar. Korean J Parasitol 2015; 53: 619-625. https://doi.org/10.3347/kjp.2015.53.5.619

14. Sieu TP, Dung TT, Nga NT, Hien TV, Dalsgaard A, Waikagul J, Murrell KD. Prevalence of Gnathostoma spinigerum infection in wild and cultured swamp eels in Vietnam. J Parasitol 2009; 95: 246-248. https://doi.org/10.1645/GE-1586.1

15. Le XT, Rojekittikhun W. A survey of infective larvae of Gnathosto$m a$ in eels sold in Ho Chi Minh City. Southeast Asian J Trop Med Public Health. 2000; 31: 133-137.

16. Saksirisampant W, Thanomsub BW. Positivity and intensity of Gnathostoma spinigerum infective larvae in farmed and wildcaught swamp eels in Thailand. Korean J Parasitol 2012; 50: 113118. https://doi.org/10.3347/kjp.2012.50.2.113

17. Rojekittikhun W, Chaiyasith T, Butraporn P. Gnathostoma infection in fish caught for local consumption in Nakhon Nayok Province, Thailand. II. Seasonal variation in swamp eels. Southeast Asian J Trop Med Public Health 2004; 35: 786-791.

18. Sugaroon S, Wiwanitkit V. Gnathostoma infective stage larvae in swamp eels (Fluta alba) at a metropolitan market in Bangkok, Thailand. Ann Clin Lab Sci 2003; 33: 94-96.

19. Saksirisampant W, Kulkaew K, Nuchprayoon S, Yentakham S, Wiwanitkit V. A survey of the infective larvae of Gnathostoma spinigerum in swamp eels bought in a local market in Bangkok, Thailand. Ann Trop Med Parasitol 2002; 96: 191-195. https:// doi.org/10.1179/000349802125000295

20. Cole RA, Choudhury A, Nico LG, Griffin KM. Gnathostoma spinigerum in live Asian swamp eels (Monopterus spp.) from food markets and wild populations, United States. Emerg Infect Dis 2014; 20: 634-642. https://doi.org/10.3201/eid2004.131566 
